\title{
Analysis of naphthoquinone derivatives as topoisomerase I inhibitors using fragment based QSAR
}

\author{
Bastikar Virupaksha ${ }^{1 *}$, Gupte Alpana ${ }^{2}$, Khadke Prashant $^{1}$, Deshpande Uday ${ }^{2}$, Desideri Alessandro ${ }^{3}$ \\ From 8th German Conference on Chemoinformatics: 26 CIC-Workshop \\ Goslar, Germany. 11-13 November 2012
}

In this study an attempt was made to understand the structural requirements for Topoisomerase I (Topo I) inhibition using a novel Group based QSAR (GQSAR) or fragment based QSAR technique. Here we combined the GQSAR technology with conventional 2D and 3D QSAR to derive GQSAR models for various reported naphthoquinone derivatives. Various regression models such as Multiple Regression (MRA), Partial Least Square (PLS) and Principal Component Analysis (PCA) as well as k-Nearest neighbor (k-NN) QSAR were used to develop several combined 2D and 3D GQSAR models. The GQSAR analyses revealed the importance of Geometrical topological indices and Baumann's alignment independent topological descriptors along with dipole moment and other general descriptors like HBonddonor and XYHydrophilic etc for governing the activity variation. Further the GQSAR showed that chemical variation like presence of substituted double bonded $\mathrm{C}$ atom separated from oxygen by 6 bonds and HBonddonor count are highly influential for achieving highly potent Topo I inhibitors. The Naphthoquinone derivatives having 2- $\mathrm{CH}(\mathrm{OX})$ $(\mathrm{CH} 2 \mathrm{CH}=\mathrm{CMe} 2)-5,8$-dihydroxy-1,4-naphthoquinone substitutions are most important fragments for the inhibitory activity. In addition the k-nearest neighbor classification model resulted in 3 important descriptors like moment of inertia, quadrapole and hydrogen count. The developed models are interpretable with good statistical and predictive significance and can be used for guiding ligand modification for development of potential new Topo I inhibitors. From the present study it can be seen that the substitutions made on $2-\mathrm{CH}(\mathrm{OX})-(\mathrm{CH} 2 \mathrm{CH}=\mathrm{CMe} 2)-5,8$ -

* Correspondence: vabastikar@gmail.com

${ }^{1}$ Department of Bioinformatics, JJT University, Rajasthan, India

Full list of author information is available at the end of the article dihydroxy-1,4-naphthoquinone position can result in better Topo I inhibitors.

\section{Author details}

'Department of Bioinformatics, JJT University, Rajasthan, India. ${ }^{2}$ Rajiv Gandhi Institute of Biotechnology and IT, Bharti Vidyapeeth, Pune, Maharashtra, India. ${ }^{3}$ Department of Structural Biology, University of Rome Tor Vergata, Rome, Italy.

Published: 22 March 2013

\section{doi:10.1186/1758-2946-5-S1-P22}

Cite this article as: Virupaksha et al: Analysis of naphthoquinone derivatives as topoisomerase I inhibitors using fragment based QSAR. Journal of Cheminformatics 2013 5(Suppl 1):P22.

\section{Publish with ChemistryCentral and every scientist can read your work free of charge \\ "Open access provides opportunities to our colleagues in other parts of the globe, by allowing anyone to view the content free of charge." \\ W. Jeffery Hurst, The Hershey Company. \\ - available free of charge to the entire scientific community \\ - peer reviewed and published immediately upon acceptance \\ - cited in PubMed and archived on PubMed Central \\ - yours - you keep the copyright \\ Submit your manuscript here: \\ http://www.chemistrycentral.com/manuscript/

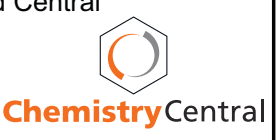

